\title{
DIGITAL TECHNOLOGY IN THE PROTECTION OF CULTURAL HERITAGE BAO FAN TEMPLE MURAL DIGITAL MAPPING SURVEY
}

\author{
Yu ZHENG \\ Cultural Heritage Conservation Centre (CHCC), Beijing Guo Wen Yan Information Technology Co., Ltd., \\ Beijing, China - blizza@chcc.org.cn
}

KEY WORDS: Three-dimensional Laser Scanning, Mural Digital Mapping Survey, Degradation Investigation

\begin{abstract}
:
Peng Xi county, Sichuan province, the Bao Fan temple mural digitization survey mapping project: we use three-dimensional laserscanning, multi-baseline definition digital photography, multi-spectral digital image acquisition and other technologies for digital survey mapping. The purpose of this project is to use modern mathematical reconnaissance mapping means to obtain accurate mural shape, color, quality and other data. Combined with field investigation and laboratory analysis results, and based on a comprehensive survey and study, a comprehensive analysis of the historical Bao Fan Temple mural artistic and scientific value was conducted. A study of the mural's many qualities (structural, material, technique, preservation environment, degradation, etc.) reveal all aspects of the information carried by the Bao Fan Temple mural. From multiple angles (archeology, architecture, surveying, conservation science and other disciplines) an assessment for the Bao Fan Temple mural provides basic data and recommendations for conservation of the mural.
\end{abstract}

In order to achieve the conservation of cultural relics in the Bao Fan Temple mural digitization survey mapping process, we try to apply the advantages of three-dimensional laser scanning equipment. For wall murals this means obtaining three-dimensional scale data from the scan of the building and through the analysis of these data to help determine the overall condition of the settlement as well as the deformation of the wall structure. Survey analysis provides an effective set of conclusions and suggestions for appropriate mural conservation. But before data collection, analysis and research need to first to select the appropriate scanning equipment, set the appropriate scanning accuracy and layout position of stations necessary to determine the scope of required data.

We use the fine features of the three-dimensional laser scanning measuring arm to scan the mural surface deformation degradation to reflect the actual state of the mural surface patch model. For the degradation of the surface of the pigment layer, we use the patch model to simulate the scan obtained from an analysis. Statistics calculated relatively objective mural surface area from volume data, providing more accurate quantitative data for the mural conservation, especially, providing a viable technology for accurate monitoring of continued degradation.

We believe, in order to make use of the three-dimensional laser scanning technology in a digital heritage conservation application, the technology should not only be used to record the object geometry and play a role in record keeping aspects, but, rather, should be used during the investigation to protect against targeted degradation and a more meaningful interpretation function. Like the development of the medical application of X-ray technology not only retains a picture, but more importantly, through this technical interpretation of patient pathology, guides doctors in carrying out the treatment work. Therefore, in the process of digitization of cultural heritage research, the focus should shift to the use of digital technology in the analysis of heritage object degradation and degradation monitoring surveys can promote the application of digital technology in the conservation of cultural heritage.

\section{BAO FAN TEMPLE MURAL DIGITIZATION SURVEY MAPPING PROJECT}

The development of digital technology and of three-dimensional laser scanning in the last decade has been rapid. This technology has a wide range of application in the research of cultural heritage and has been used in an increasing number of cultural heritage digitization projects. Three-dimensional laser scanning in cultural heritage research has become an especially hot topic. Looking at how this technology is used in current cultural heritage research work, this technology is used with an emphasis on digital information collection and display, or as a basis for mapping work (generating content reflecting the heritage object geometry orthophotos and other physical characteristics.) How to use this technology to provide more direct technical support for cultural heritage protection? How to use digital tools to achieve cultural degradation qualitative and quantitative survey positioning? How to make use of the advantages of digital technology in the cultural aspects of degradation surveillance? Conservation work needs to achieve direct data support. Work in these areas still appears not deep enough. In short, digital technology as a new tool is currently mainly used as a camera, but use as a medical tool for conservation has not been fully exploited.

Peng Xi county, Sichuan province, the Bao Fan temple mural digitization survey mapping project: we use three-dimensional, laser-scanning, multi-baseline definition digital photography, multi-spectral digital image acquisition and other technologies for digital survey mapping. The purpose of this project is to use modern mathematical reconnaissance mapping means to obtain accurate mural shape, color, quality and other data. Combined with field investigation and laboratory analysis results, and 
based on a comprehensive survey and study, a comprehensive analysis of the historical Bao Fan Temple mural artistic and scientific value was conducted. A study of the mural's many qualities (structural, material, technique, preservation environment, degradation, etc.) reveal all aspects of the information carried by the Bao Fan Temple mural. From multiple angles (archeology, architecture, surveying, conservation science and other disciplines) an assessment for the Bao Fan Temple mural provides basic data and recommendations for protection of the mural.

The Bao Fan Temple, has been designated as one of the sites for the Sixth National Cultural Relics Protection, and is located in Bao Fan township, Peng Xi county, Sichuan province. Bao Fan temple is an abbey consisting of two courtyards and eight heritage structures: shan men (mountain gate), tian wangdian (king hall), dong xi xiang fang (the east and west wings), da xiongdian (main hall), hou dong xi xiang fang (rear east and west wings), and the Guan Yin dian (goddess Guan Yin hall). The temple has a total construction area of $1647 \mathrm{~m}^{2}$. The temple mural is divided into two parts: one in the Main Hall (da xiongdian) for murals painted in the Ming dynasty, as well as the hall arch eye, wall murals and painted ceilings with a total area of $157.89 \mathrm{~m}^{2}$. The other is a four-section mural (named zhu tian chao gong) created during the Ming Dynasty from the nearby Ding Jing temple, which was moved to the Guan Yin halland has a total area of $26.36 \mathrm{~m}^{2}$.

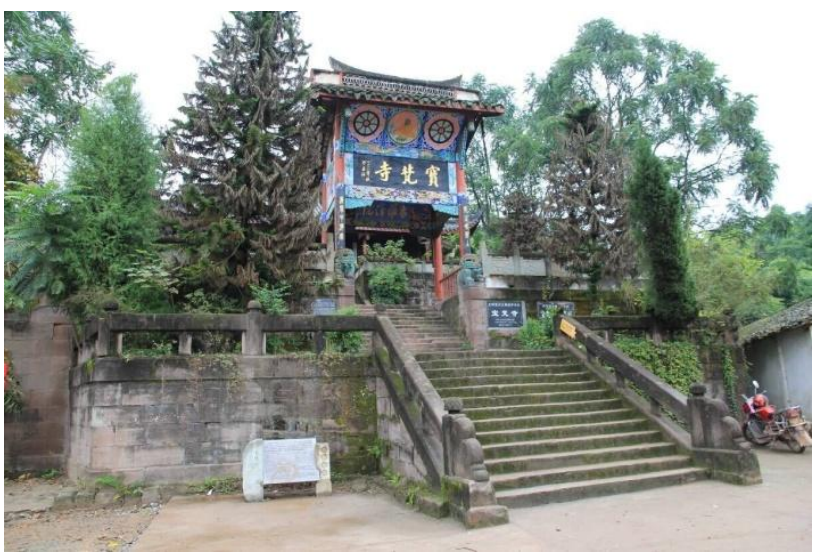

Figure 1 Bao Fan Temple Shan Men (Main Gate).

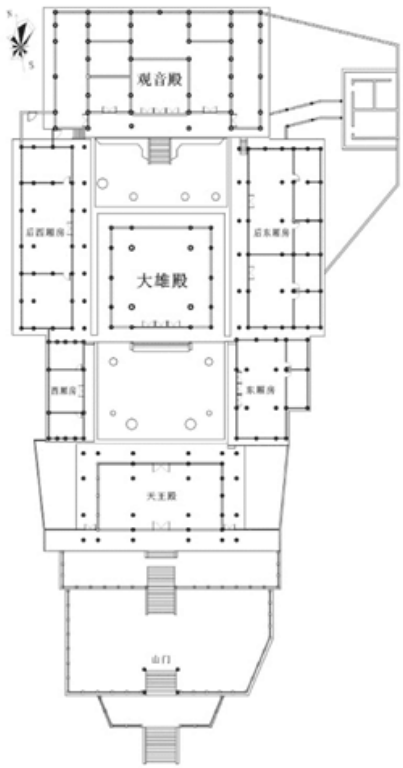

Figure 2 Bao Fan Temple Layout
The Bao Fan Temple mural is a precious example of ancient physical relics and a resource for understanding its drawing history, production process, structure and materials. With indepth exploration, we can understand the geographical and historical context of the mural creation process, not only for the locality of the mural, but also for the Sichuan region and even across the country. This allows us to sift through the differences in the production process of the use of mural materials, looking for common characteristics, commonalities and features. In addition, a more complete form, color mural to extract data from the inherent nature of the external, from the creation of the mural carried interpretation of history, art, science, economy, culture and other information as detailed as possible so far, but also for the Bao Fan mural after study protection measures to develop a reasonable, prudent to provide more scientific data to support. The digital survey mapping using a variety of techniques, murals were fine digital mapping survey of the history of mural drawing making crafts and drawing materials in-depth interpretation.

\section{DIGITAL TECHNOLOGY ASSISTED MURAL HISTORICAL RESEARCH}

Past studies suggest that the main hall mural is divided into two stages, the east end of the south wall mural style is distinctly different from the other piece of the painting which is considered to be from the late Qing dynasty, and the other nine wall mural were pure Ming dynasty. But through this survey and digital mapping, there are a lot of reconstructed details that can be speculated to be from the Ming dynasty to the late Qing dynasty. It also received, at least once, a large scale color refill. According to the investigation the Main Hall mural was created and reconstructed through three periods of time.

Period one, created when the Bao Fan temple main building was constructed in Chenghua years (1465-1487), Ming dynasty. The mural is based on the Chinese couplet "ran su zhu luo han, tu hua xi fang jing" describing a bodhi wonderland. Nine preexisting mural were the product of the Ming dynasty, although the nine paintings were reconstructed, retraced, and even regilded, the mural still shows the original skills of the Ming. The survey and mapping digitized by means of high definition image recording, multi-spectral, hyper-spectral and other tech detection to show the detail of the original mural of Ming dynasty. For example as image A10, retain fine Ming style including a detailed portrayal of the Dragon and Phoenix and the Passion Flower (passiflora caerulea) border. Image A03 the tiger in the center bottom of the mural is drawn using the technique of a silky method to provide the illusion of a realistic coat of fur, resulting in difficulty for the artists to recreate the same affect, the differential in color is because the tiger is the original.

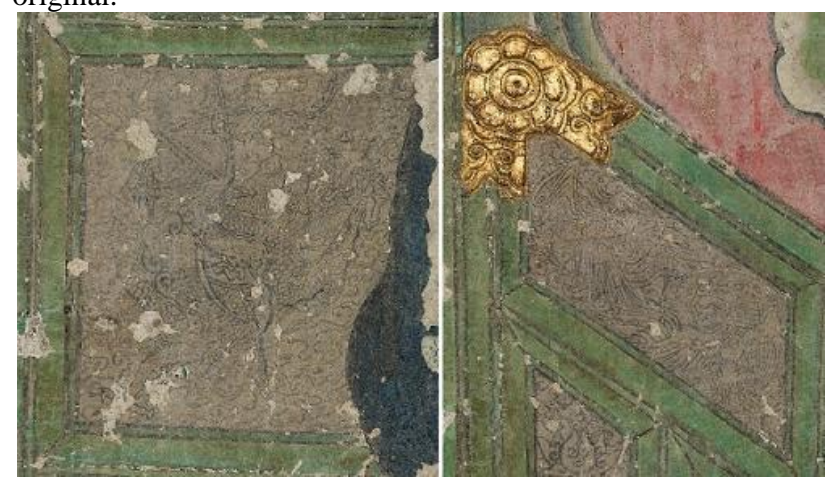

Figure 3 A10 mural image 




Figure 4 A03 mural image

The second period is in the Qing dynasty between $38^{\text {th }}$ year of the Emperor Kangxi (1699) and the $24^{\text {th }}$ year of the Emperor Qianlong (1759). More than 200 years after the creation of the mural, the mural was in disrepair and unclear, the temple monks hired a painter to reconstruct the painting on a larger scale. The mural we see today is the work of that artist. The text on the mural was covered, by multi-spectral detection the text can be clearly read:qing yi mao nian ben shan shi zi kou hua (during the yi mao year of Qinq dynasty, the monks collected alms to fund the restoration).This text helps identify the date of the restoration.

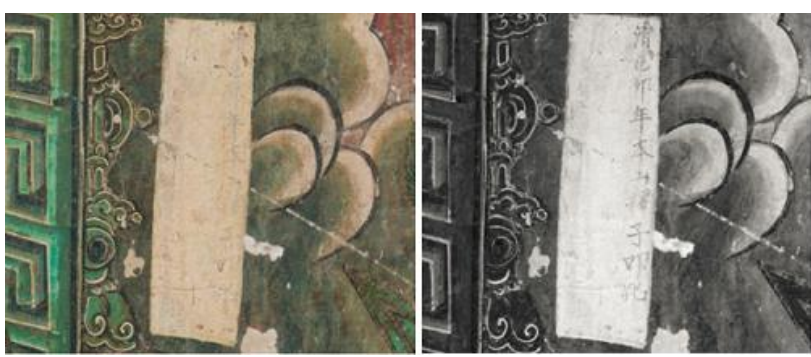

Figure 5 The text

The lunar calendar during the Qing dynasty had five special years referred to as yimao year these occur approximately every 60 years specifically during the $4^{\text {th }}$ year of the Emperor Chongde (1639), the $38^{\text {th }}$ year of the Emperor Kangxi (1699), the $24^{\text {th }}$ year of the Emperor Qianlong (1759), the $24^{\text {th }}$ year of the Emperor Jiaqing (1819), and the $5^{\text {th }}$ year of the Emperor Guangxu (1879).The second period mural style differs from the third period's style quite drastically, indicating a big time difference between. Therefore, the second period mural restoration should be dated earlier than yimao year occurring during reigns of either Emperors Guangxu or Jiaqing (i.e., before 1819). During the $4^{\text {th }}$ year of the Emperor Chongde (1639), the Qing army has not yet gained control of the Sichuan region. Therefore, it can be surmised that the restoration happened between the $38^{\text {th }}$ year of the Emperor Kangxi (1699), the $24^{\text {th }}$ year of the Emperor Qianlong (1759).

The second period mural painter did not change the composition of Ming murals, roughly based on the color of the first phase of recoloring and retracing. The existing main building mural contains many of traces of the restoration. Image A03 the original had a white base with black patterns after years of erosion the constructors painted the base black with white patterns. The second periods mural techniques became lacking compared to the first, part of the process is rougher. Excess use of paint made the mural embossed, laced with gold and quite rough. The restoration used embossed painting laced with gold rather than the original gilding or to describe many floral regions. In some plaster damaged areas the plaster was not replaced before gilding causing it to become concave. As the paint aged, pieces flaked off; instead of replacing the pieces, the restoration painted over the original.

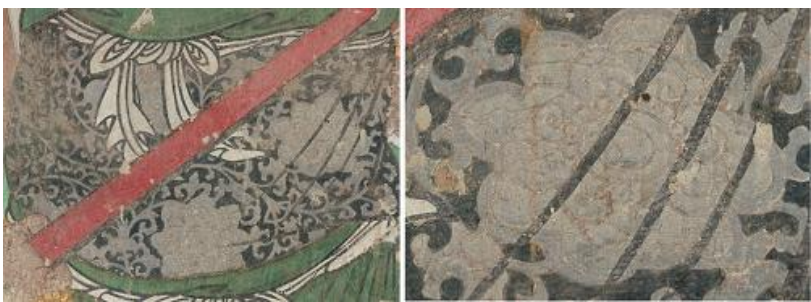

Figure 6 A03 mural image, the constructors painted the base black with white patterns

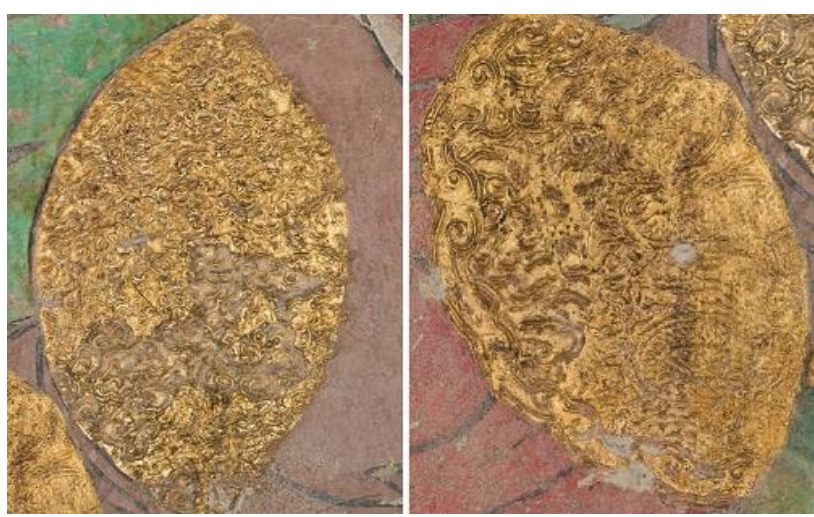

Figure 7 A04 mural image, the damaged plaster was not replaced before gilding causing it to become concave

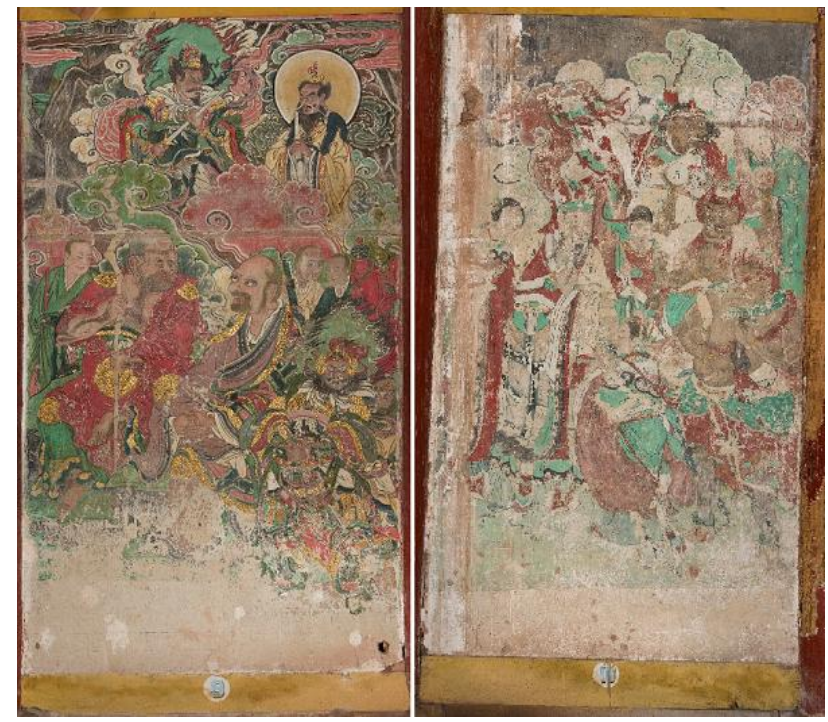

Figure 8 Image A12 (right) is part of the third period, the picture's composition and color compared to other murals (left) are quite different presenting the mural as late Qing.

\section{FIELD INVESTIGATION AND LABORATORY ANALYSIS ASSISTED MURAL STRUCTURE AND MATERIAL RESEARCH}

Through field observation it is clear that the Bao Fan temple mural's basic structure is similar to the traditional method used in the Sichuan regionincluding basic support, plaster layer and pigment layer. Unlike other murals the Main Hallmural is in the place of its origin. The building of the network of structural supports sandwichesbamboo walls.Because the building support 
settled, the structural network tipped and the bamboo walls and associated framing rotted. Due to the presence of a certain degree of rotting, the mural suffered severe overall deformation and degradation. This included deformation of the overall shape, hollowing of the paint and cracking of the mural. The mural in the Guan Yin Hall has been moved from another place. This requires different methods of protection similar to what might be used in a museum. The basic structure includes a wooden keel and fiber-reinforced plastic (FRP) for support. The original plaster, as well as the plaster layer, white powder layer, the pigment layer and the outer frame were maintained with the mural. This protected structure is moveable.

The Main Hall mural's composition is rich in color with mostly a green base. The colors include red, yellow, white, gold, etc. In addition to the use of conventional solids, there is a rage of color mixing, making the overall picture more realistic. At the site, samples of mural damage were collected using a resinembedded section. The structure of the pigment layer of the murals are observed microscopically. The results showed that due to the difference in size of the pigment particles themselves, the amount of coloring required were different, so that the pigment layer thickness of different colors were not the same. Interestingly, there are slight differences gilding between the Main Hall mural and the Guan Yin Hall mural. In the Main Hall, the mural is decorated with a process including embossed paint gilding and flat paste two-layer technology. It can be seen from the microscopic cross-sectional structure of the paint used in the embossed layer; the gilding thickness is only about 0.01 $\mathrm{mm}$. The Guan Yin hall mural uses less gold; the only part to use gold was the hair adornment and jewelry of the figures. Field observations and laboratory profile observations indicate the gilding technology is different: the thickness of the gilding is $0.05 \mathrm{~mm}$. This results in a more gold and less shiny gilding. Based on this, we can tell that the gilding of Guan Yin Hall mural is probably original Ming Dynasty and that of the Main Hall mural is most likely from the Qing Dynasty restoration.

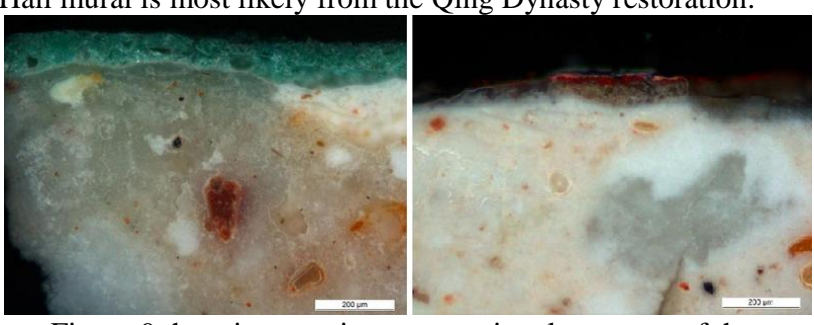

Figure 9 the microscopic cross-sectional structure of the pigment green and red in Main Hall mural

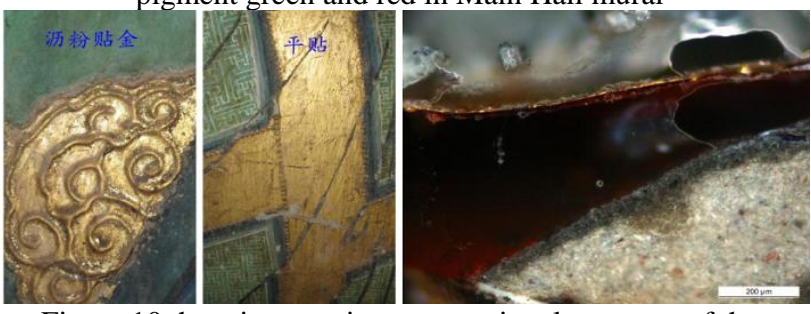

Figure 10 the microscopic cross-sectional structure of the gilding in Main Hall mural

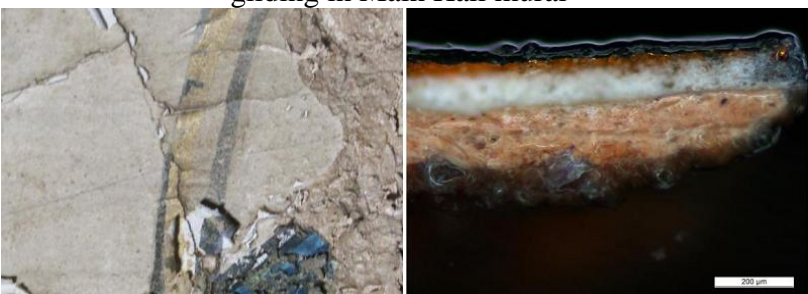

Figure 11 the microscopic cross-sectional structure of the gilding in Guan Yin Hall mural
Mural paint analysis was mainly conducted in two ways: 1, hyper-spectral shooting: a non-destructive method to analyze the color; and 2, collection of small samples for use in laboratory analysis. During the elemental analysis in the laboratory, x-rays were used for phase-composition analysis. The analysis also used Raman Spectroscopy. The results of all these analyses were combined to completely determine the material and structure of the mural.

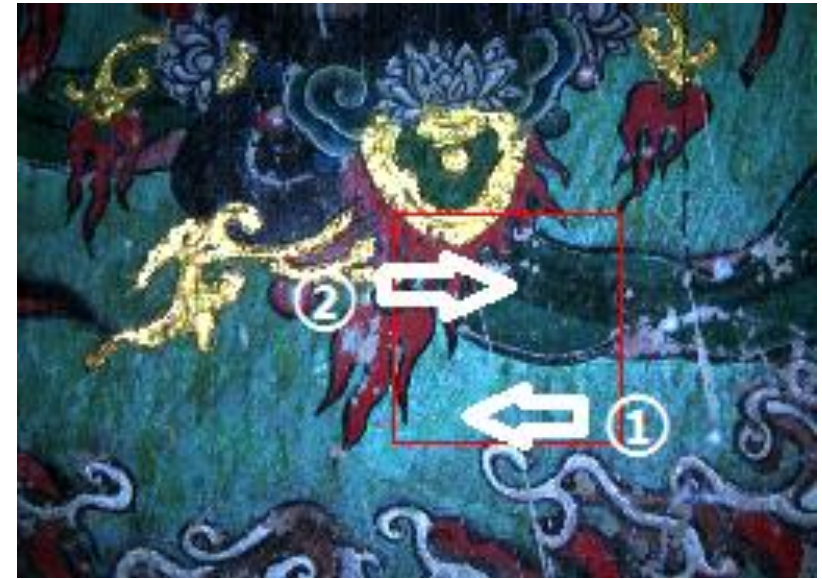

Figure 12 hyper-spectral shooting area of green

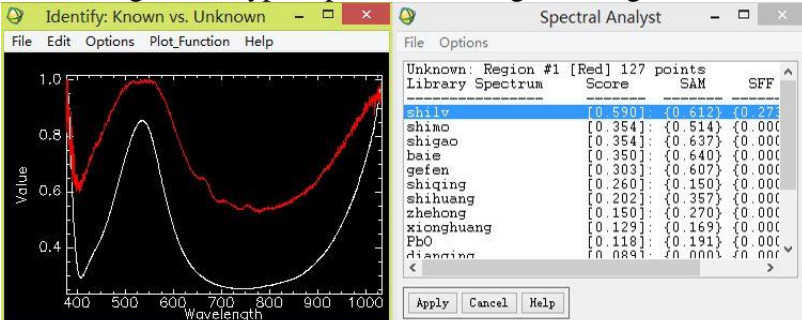

Figure 13 hyper-spectral shooting result of light green

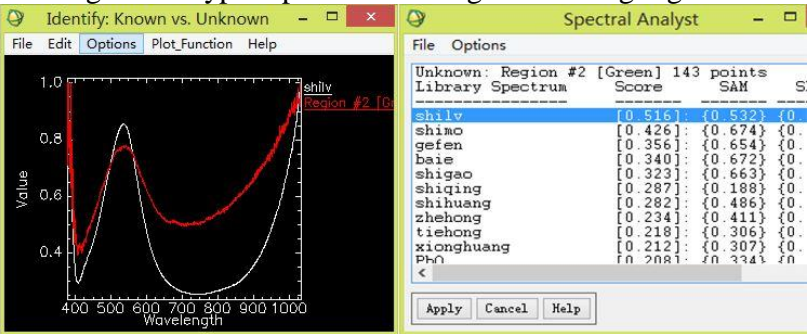

Figure 14 hyper-spectral shooting result of dark green

After analyzing a number of ways, it was detected that the Main Hall and Guanyin Hall murals mainly used mineral pigments. The green is malachite for image and technique, differing in texture and thickness there are three types of green. The blue is azurite;microscopic observation and hyper-spectral results show that in the process of mixing colors either white or black is applied in order to produce different levels of color. The red is mainly cinnabar with a little bit of red lead and some iron red. The black is carbon black. The white is white lead. The yellow is most likely litharge. The white powder layer of the Main Hall mural is chalk and quartz. The Guanyin Hall mural uses plaster and baked plaster, the plaster layer contains chalk, quartz and montmorillonite.

We also recorded color information. For the Main Hall mural's rich color condition, not only are blue, green, red, black etc. highly pure but also the light red, flesh, grey and all kinds of mixed color. After the paint ages the original color fades and will continue to fade. The survey used a spectro-photometer in the lab to measure color information and spectral data features 
under the standard light source. In total approximately 100 color samples were collected. A color recording device was used. Spectral data indicate the characteristics of material and the spectral data of every color has uniqueness and objectivity (this excluded the interference of ambient light.) So by using the photometer we can monitor the color change that the human eye cannot tell. Periodically monitoring the color information and environmental information produces results that can help with maintain the correct environment to preventative protection of the murals.

\section{DIGITAL TECHNOLOGY ASSISTED MURAL DEGRADATION INVESTIGATION}

The objectives of the BaoFan Temple Mural digital survey mapping included preparation of written records, site investigation, and preparing a wholly digitized archive. Other objectives included evaluating the state of murals, using deep analysis to determine elements threatening the long term stability of the murals, and also to support the protection, monitoring, and maintenance of the murals.

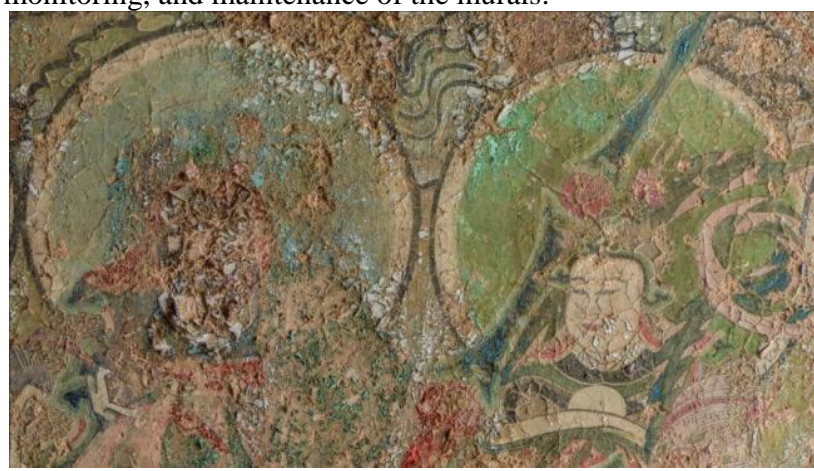

Figure 15 The degradation of mural

The digitization work we did is all for the needs of heritage protection and data collection. The collected data can be used for further monitoring and reconstruction. Using the digitization skills to recognize and provide statistics to help determine the level of degradation and the characteristics there of. Despite the focus on degradation of the murals themselves, much degradation are coming for the mural carrier. In the Main Hall mural long cracks generally appear at the same height. The root cause of these cracks is how the wall carries the mural and also the building structure related to the wall. We used a middledistance scanner for a scan analysis of the overall wall carryings the mural. Figure 16 shows the Main Hall east wall shape changes for the four section mural. In the vertical direction as the standard plane color changing form red to blue represents a wall concavity and blue to red represents convexity changes. From the rightmost two sections, we can see that the upper part has an inward tilt of about 10 centimeter. The bottom corner of the rightmost section has a backward depression and not on the same plane with the other parts of the mural.

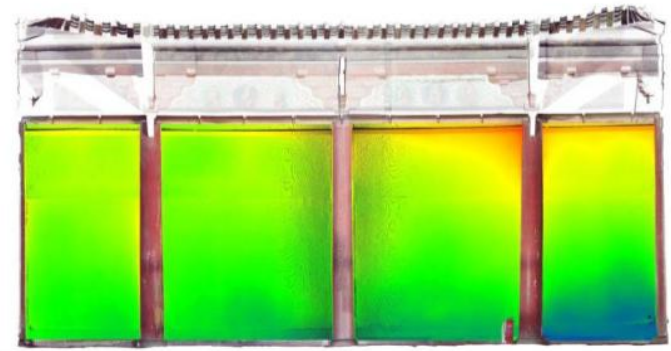

Figure 17 the Main Hall east wall shape changes for the four section mural

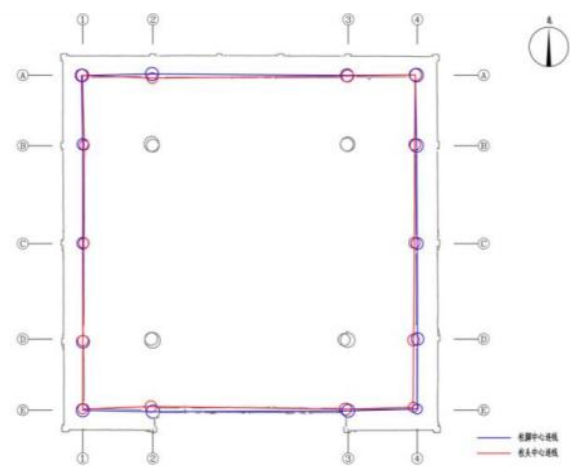

Figure 18 The image above shows a 3-D scan used to compare the offset of building stigma and column foot in the Main Hall.
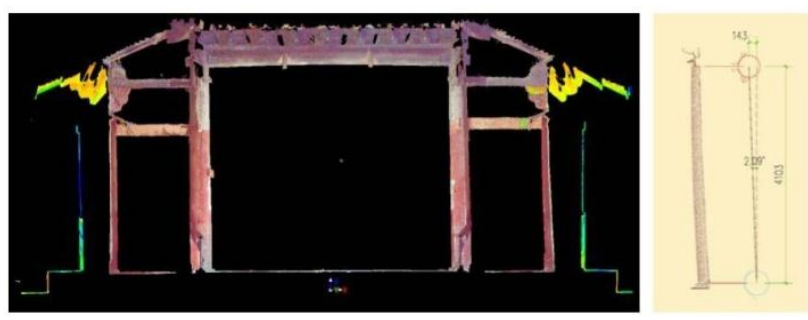

Figure $193-\mathrm{D}$ point cloud section of the Main Hall

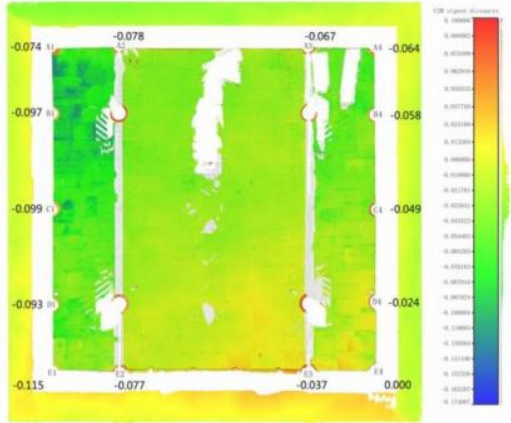

Figure 20 the Main Hall foundation and ground shape changes

Figure 21 shows a 3-D point cloud section cutting of the Main Hall front cave gold column and indicates a tilt in the structure. From precision 3D data measurement, the east column cap tilted $143 \mathrm{~mm}$ to the west. A reasonable amount of tipping might be $50 \mathrm{~mm}$, but this column tipping is far in excess of this amount. This is due to uneven sinking of the column foundation. This is due to loading of the building framework causing deformation. In the Figure 22 image, according to the data we parsed, for the Main Hall the column foundation, there exists a height difference of $115 \mathrm{~mm}$ between the highest point in the south east and the lowest point in the southwest. This causes the whole structure to tilt and deforms the mural wall.

Some wall damage is not only caused by the column tipping but is also related the wall structure itself. Figure 19 shows the Main Hall west wall four section mural overall shape. This shows that part of the wall projecting inward and the shape changing evenly. This is possibly related to the overall structure and deformation. Another part of the wall, below the overall plane, maybe related with the sandwiched bamboo wall structure. A detailed look at the image above clearly represents the first mural towards south west side. Through field observation it is difficult to discover the shape change of the upper area of the mural, but the scanner easily discovered the change in shape. 

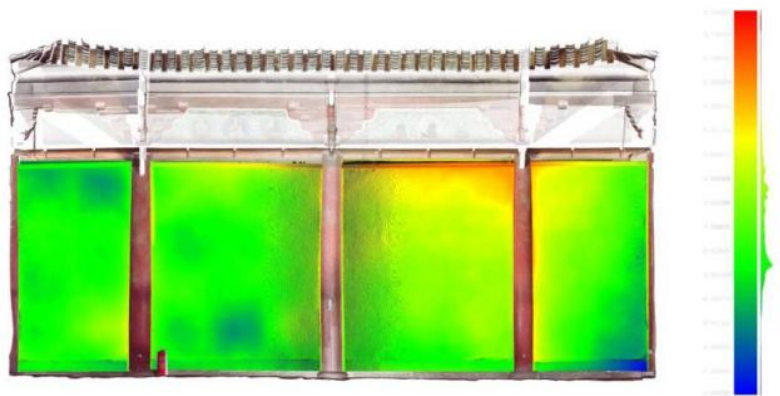

Figure 1923 the Main Hall west wall shape changes for the four section mural
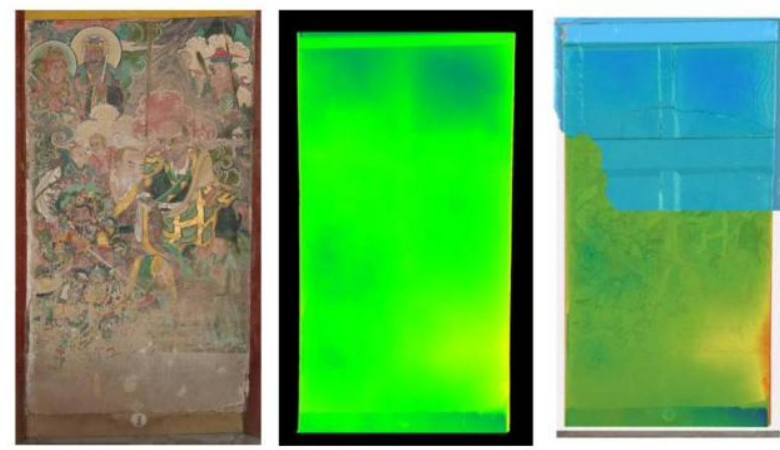

Figure 2024 A scan of the back of the mural wall indicates the structure of the bamboo inside is deforming

We used a 3D laser scanning survey and a middle-distance scanner with a dot density is 1.5-3 millimeter and a measurement error less than two millimeter; these are sufficient to determine the surface degradation of the murals itself.

Digital technology also can take advantage of the automatic quantification computing. Preliminary investigation determined the degradation situation which mainly includes fissure, hollowing, cracking, peeling, salt crystal formation, pigment shedding, animal damage, vandalism etc. The appearance of the degradation can be used to categorize the defects as shape, color or quality changes.

The shape changes include big changes: wall shape changes, fissure, hollowing, etc.More subtle changes include peeling, cracking, nicks, etc.. A color change refers tochanges in the color or grain of the mural appearance such as pigment shedding water logging, graffiti, cover, fade and color degradation. A quality change refers to a change in the material quality change at different layers such as a change in alkalinity, salt crystal formation, chalking, etc.
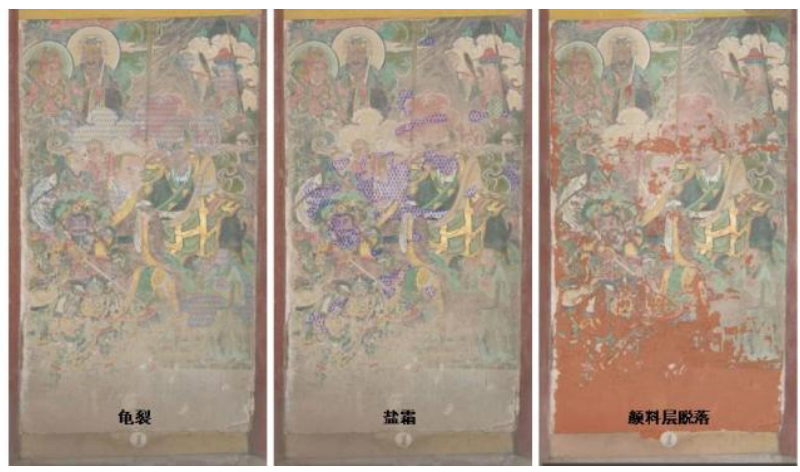

Figure 2125 degradation map of mural yi fu fo hui
Silhouette optical imaging is a kind of digitized tool: by emitting light from the side we can observe more subtle effects such as cracking, peeling, pigment shedding, salt formation etc. This mural depicts yi fu fo hui (a meeting of the gods). Its total area is $7.58 \mathrm{~m} 2$. Cracking occupies $0.74 \mathrm{~m} 2$ this is $9.76 \%$ of the total; salt formation occupies $0.39 \mathrm{~m} 2$ (5.15\%); pigment peeling occupies $1.83 \mathrm{~m} 2(24.14 \%)$.

In our experience of practical operation a silhouette light image accuracy of $75 \mathrm{dpi}$ is required to be able clearly distinguish defects.
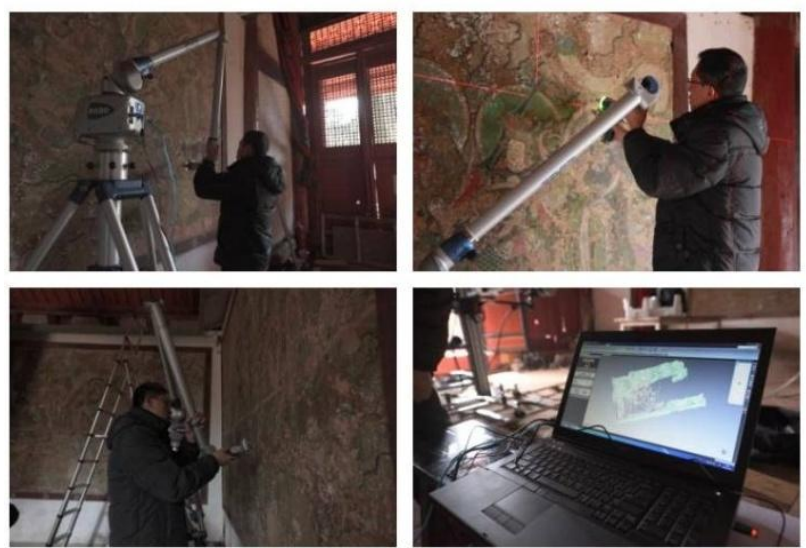

Figure 22 use arm of a laser scanner to develop a good 3D model of the mural surface

We always believed 3D digital technology application in cultural heritage protection should not just be used for recording the subject, geometry, shape, record keeping, but should also be used to deeply diagnose the levels of degradation so that we can make the protection of cultural heritage more scientifically express problems with data and facts. Like the development of the medical application of X-ray technology not only retains a picture, but more importantly, through this technical interpretation of patient pathology, guides doctors in carrying out the treatment work. All of the work we did used digital technology such as 3D laser scanning to conduct a certain level of degradation recognition and surveying.

For example, for pigment peeling analysis, we took advantage of the long arm of a laser scanner to develop a good 3D model of the degradation. Figure 23 is an enlargement of the pigment peeling for the Guanyin Hall mural. Much of the color layer used alum water which is affected by environmental humidity which causes the layer to curl. The middle image is an enlargement actual pigment curling. The bottom image is a computer simulation of the surface without the pigment curling and from which we can observe many empty areas and the actual distribution of peeling. After the computer has conducted an accurate calculation of the empty area (without the pigment peeling), we can determine the peeling occupied $0.1309 \mathrm{~m} 2$ or $19.62 \%$ of the total area.

After all of this work, we now have a very detailed survey of the Bao Fan mural degradation. The Main Hall has ten sections of murals with fourteen forms of degradation and deformation. Including one-time damage such as animal damage, pigment separation, vandalism, human contact damage, nicks, waterlogging, etc. Continuing degradation including changes in alkalinity, fissuring, hollowing, cracking, peeling, salt crystal formation, mud logging, etc. constitute a big threat to the murals. The most urgent threats is the structural degradation including 
wall shape changes, large transverse crack formation as well as insect damage. The degradation and deformation statistics are shown in the table above.



Figure 2326 use 3D laser scanning for pigment peeling analysis
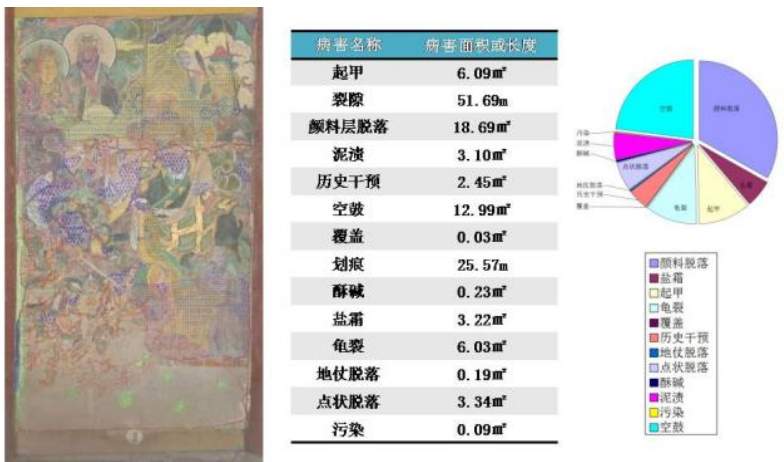

Figure 2427 detailed survey of the Bao Fan mural degradation

We can see that continuing degradation related to the environmental humidity, and which is difficult to control, affects $16.8 \%$ of the Main Hall mural. In conclusion the next step, based on the result of the past survey mapping, is to develop a plan to prevent the mural from being destroyed any further and begin the reconstruction of the mural.

\section{AN ANSWER}

As we investigate digitization further, the question in hand is "have we utilized digital technology to its maximum effectiveness in cultural heritage conservation?" Our best theory is that the cultural heritage digital protection is simply a tool, a tool that will be used to preserve the cultural antiques of our great nation. This tool supplements basic research so that all of the data can be accurately captured. The tool is used for data collection and allows us to archive and easily access the details of the cultural heritage project. The tool can also be used to analyze, qualify and quantify the existing degradation and provide accurate data for heritage protection and maintenance. Through these two methods the purpose of heritage interpretation and conservation can truly be realized. We have 3D laser scan, we have digital analysis, we have digital degradation survey ... all of these serve the realization of this purpose. We use different technologies for different heritage characteristics and objectives. We should choose the correct technology for the intended objective and let digital technology serve heritage conservation. 